\title{
Optimized Approach for Collaborative eLearning using Real-Time Social Networks
}

\author{
Essam Shaaban \\ Faculty of Business Technology, Canadian International College - Cairo, Egypt \\ Email: essam_shaaban@cic-cairo.com \\ Mona Nasr \\ Faculty of Computers and Information, Helwan University - Cairo, Egypt \\ Email: m.nasr@helwan.edu.eg
}

ABSTRACT-

\begin{abstract}
With the new era of Information and Communication Technology; collaborative learning is considered to be an elearning approach where learners are able to socially interact to the others, as well as instructors. In essence, learners work together in order to expand their knowledge of a particular subject or skill. Nowadays, Social Networks could be used as an e-learning platform. One would typically log in and collaborate with other learners on a specific topic using the social network as the common working space. In this paper, a new approach is presented for collaborative learning throughout social networks. The behavior the proposed approach is presented. The proposed collaborative e-learning approach consists of three modules. The first one is mobile application which is used for collecting some data about the user and his/her interests that may be considered as a data entry process. The second module is getting some location information using the GPS of the mobile device. The third module here is matching algorithm, which will do two main functions. The first one is matching the interests of the users and displaying the results based on these interests. The second one is displaying the results and sorting it based on the nearest user.in addition to routing information.
\end{abstract}

Keywords - Collaborative, social networks, e-learning, approach, location-based learning.

\section{INTRODUCTION}

$\mathrm{T}$ Technology and its development make our life easier, reduces the distance between us, and that leads to the ability to reach each other faster and easier. The development of the technology does not include only software development, but also hardware such as mobile devices and its high capabilities and specifications. So, why we do not try to use this development and this technology in order to enhance e-learning?

If someone talks about e-learning we will notice the people who are using the internet to study and watch online courses, perhaps it was called web-based training, or online learning, or computer-based training, but it's all under the same e-learning umbrella. E-learning can encompass a wide variety of online initiatives (someone can call them e-learners) in order to increase their knowledge, can use the development and the enhancement of the technology to make their study easier and more comfortable. However, before talking about the technology, let us take a deep look at one of the main differences between e-learners and the traditional educator or learners that study at traditional campus and trainings. People have been learning for ages; to eat one had to hunt, to feel relaxed sleepy, to stay collaborate and com6pete to provide value to society. It is well documented that our society is characterized by rapidly developing and ever changing political, social, economic, educational, technological and environmental situations [1].
As figure 1 depicts that the virtual classroom and Elearning has been asynchronous, which means there is no predetermined time for the learning to take place. Everyone can go at their own place and take their time to learn what they need to know, when they need to know it. However, more synchronous e-learning is now being offered through web conferencing and chat options. The great thing about e-learning is it gives you the option to do one, or both.

On the other side, traditional learning happens at wellknown universities at specific time. If someone talks about the aspect of money and cost, it is noticed that e-learning results in a cost savings for organizations use e-learning courses to replace some of their traditional instructor-led training and traditional learning. However, if someone thinks deeply he/she will note that there will be lack of interaction and communication during e-learning process. Human beings are fundamentally social creatures. Human beings are gifted to use sight, voice, tone, facial emotion posture and gestures to interact and communicate with each other as well as with the environment. 


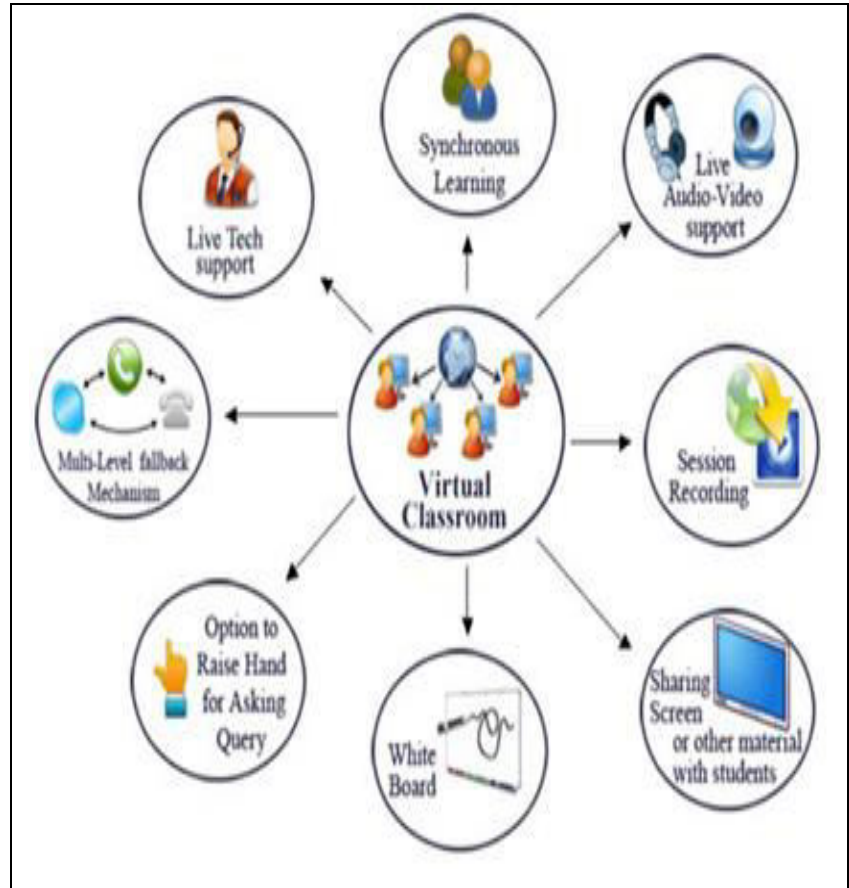

Figure 1: Virtual Classroom

Research in the literature indicates that interactive and collaborative learning environment is beneficial in achieving learning objectives because they align with the human beings' social nature [2]. Therefore, this paper aims to solve this problem and try to enhance e-learning process by enhancing some recent techniques and providing new methods that can make this process easier. This research will present an optimized approach to enhance collaborative e-Learning by Using Location based Techniques.it will present how to use the new technologies, such as Mobile devices that contains GPS. Also, creating learning groups "real groups" of e-learnings that should give a real chance for e-learners to act as traditional learners while their semester at their campus. The need for e-learning is increasing constantly and the development and the improvement of the e-learning solutions is necessary. Also, the e-learning systems need to keep the pace with the technology [3]. This paper is organized as follows: section 2 presents the literature review regarding the research area. Section 3 shows the proposed approach for collaborative e-learning based on real-time social networks. Finally, section 4 provides conclusion of this research.

\section{LITERATURE REVIEW}

E-learning is very important, but it should be made by better ways. The main problem here is the isolation in online learning activities in virtual reality, which cause a lack of communication skills and interaction between people. This lack affects the process of e-learning and also affects a nature of human beings. There is a book that is called "Connected", this book talks about the surprising power of our interaction, communication and social networks and How they shape our lives" [4]. Therefore, human beings can be defined as social creatures. "We are social not just in the trivial sense that we like company, and not just in the obvious sense that we each depend on others. We are social in a more elemental way: simply to exist as a normal human being requires interaction with other people" Atul Gawande.. Knowing e-learning Pros and Cons helps learners effectively use it as well as select proper online programs for their learning. E-learning makes learners reduce travel cost and time to and from school and study wherever they have access to a computer and Internet. It supports an adaptive learning to learners. On the other side, the fact that having a real live person that learner can ask questions of, like in a real classroom, also learners may feel isolated or miss social interaction. Interaction between students and their peers as well as their instructors is a significant aspect of e-learning. Thus, social interaction seems to be the common denominator among strategies and practices aimed at retaining online learners. To enhance retention of online learners, there should be supports for forming social network between students. [5], [6] and [7]. For that social network plays an important role to support students' learning. Through strengthening connections and inspiring communications among the learners, the learning of the whole community will be promoted. But a problem has been raised, the problem is that the university's students are better than the e-Learning's students in the means of communications, soft skills, team work, delivery commitments, learning, understanding level and practical technics.

Regarding the literature; many researchers tackle this research problem throughout many ways and approaches in order to enhance and improve collaborative learning. Creating group-learning environment has been studied that proposes a face-to-face collaborative mobile learning environment supported by wireless handhelds that allows for dynamic changes in the composition of groups while an activity is on [8]. The results show significant improvement. The advantage of mobile learning could not be fully exploited and demonstrated if the mobile learning is only conducted by using the mobile browser to access learning contents without using the native functions and features of the mobile devices. One of emerging research foci is to utilize the location-awareness of the mobile devices to further strengthen mobile learning. Previous research by Patten et al. [9] and Michie [10] have indicated that the combination of location-awareness and a contextual learning approach can facilitate learners to better construct meaningful contextualization of concepts. In addition, Choi and Kang [11] stated that e-learning gives an attractive learning opportunity for learners who are restricted by time and space, thus, increasing the number of e-learners. However, there is an issue about the high dropout rate associated with online courses. While some e-learners thrive on the increased flexibility that the medium provides, others languish in isolation and struggle to get started $[6,7]$. Therefore, as colleges continue to attract new online learners, administrators are also trying to find ways to keep them enrolled. 


\section{THE PROPOSED APPROACH}

This paper presents a specific scope about the collaborative e-learning using the new technologies in order to enhance the educational process of e-leaners and trying to solve the problem of isolation and lack of real interaction that could face every e-learner. Do the new technologies (Mobile devices and GPS) and the enhanced location-based e-learning algorithm recover the defects of traditional e-learning such as (lack of communication and real interaction)?

This research presents the usage of the new technologies in order to enhance the process of e-learning and decrease the gap between the traditional learning at real campus and the traditional e-learning and will make the interaction and the communications between the elearners more reliable and convenient for them to share their interests and knowledge. The proposed approach takes place using the mobile device and the GPS. Each elearner will have the ability to create new account on mobile application that orchestrates the interests and requests among e-learners. Figure 2 illustrates the behavior of the proposed approach.

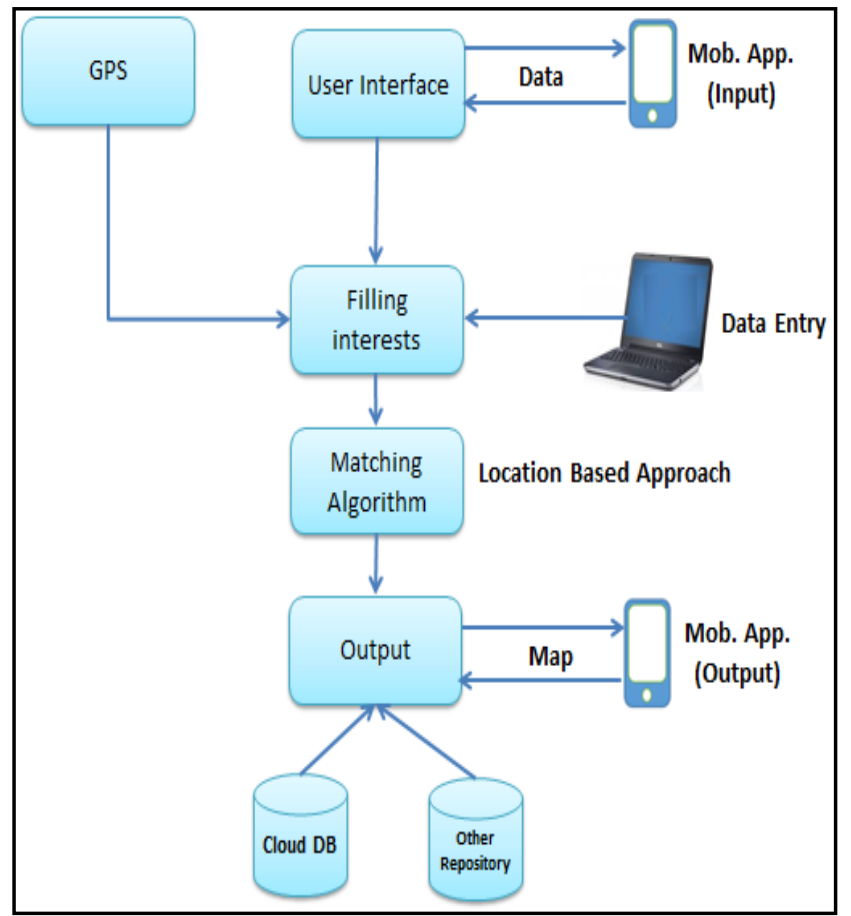

Figure 2: Behavior of the approach

As mentioned earlier; this research aims to help e-learners and allow them to meet different levels of learning objectives and Learners with similar learning type (types such as e-learners that use only learning website and elearners that interact with chatting rooms) tend to have more interactions with one another during their learning experience. Huang et al. [12] debated about specific algorithm that can help e-learners to share the knowledge and meet different learning objectives and there will be real interaction between e-learners that share the same interests. They stated an algorithm which appears in figure 3 [11]. This algorithm creates the default-learning group for the learners with similar learning profile and style in order to benefit them from the interaction in situations where collaborative learning is necessary.

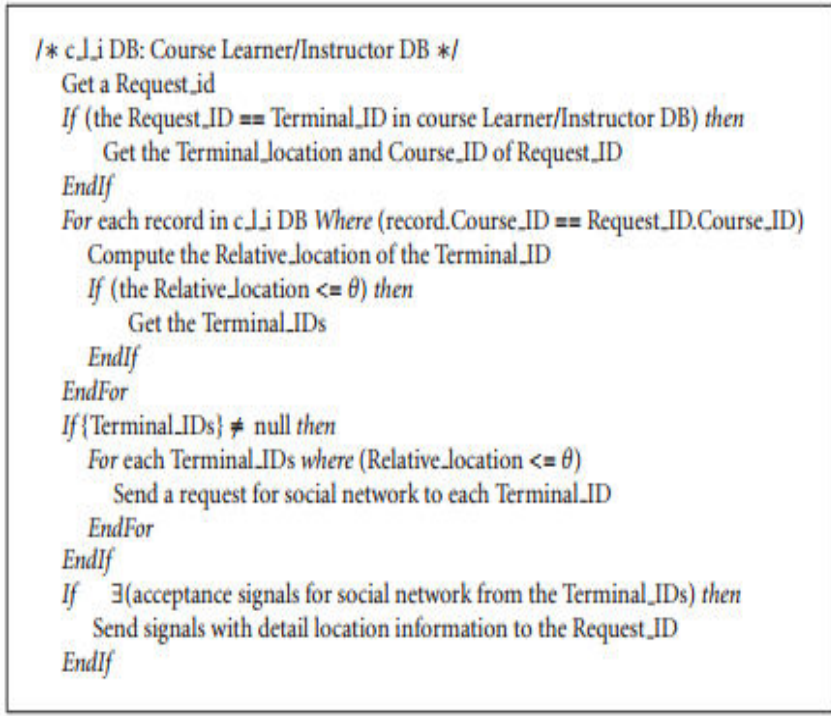

Figure 3: Location-based information management module's execution algorithm [11]

The grouping algorithm employs the Felder-Silverman learning type's model [13] to analyze learners' learning types. However, this algorithm needs some enhancement that makes the performance better, also, they didn't provide an algorithm for getting the nearest learning group which will make provide new feature for the e-learners, also they didn't provide any of routing algorithms and services which this research will provide and integrate these features, in order to enhance and improve the collaborative e-learning. Figure 4 presents the resources of getting data in the proposed approach throughout using technology resources as Mobile device and cloud database.

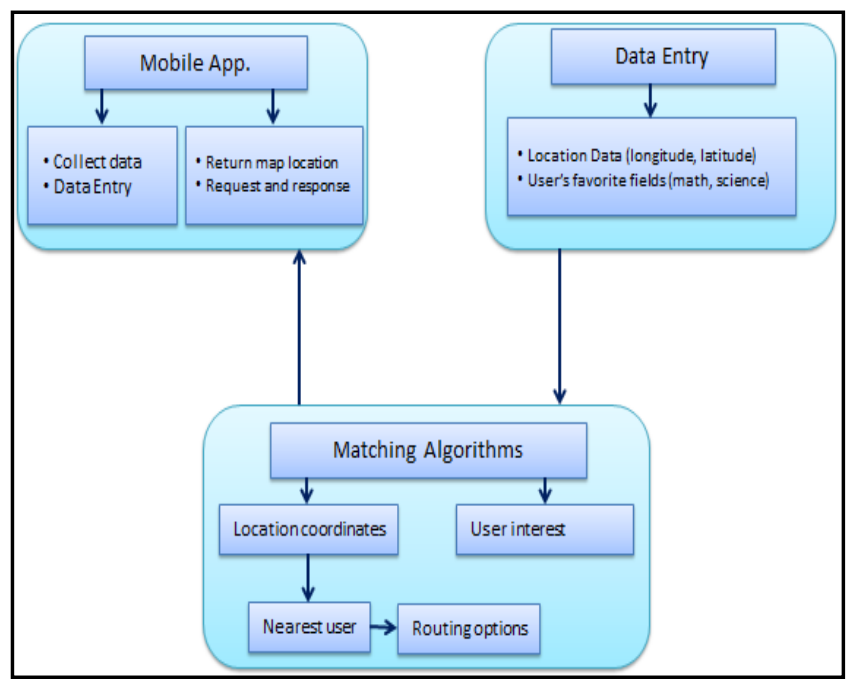

Figure 4: Modules of the proposed Approach for Data Resources. 
Simply there are three main modules the first one is the mobile application of this research that will be used for two purposes, the first one for collecting some data about the user and his interests, which could be considered a data entry process. The second purpose is to display the results of the algorithm with a simple map control with some nodes as shown in figure 5 .

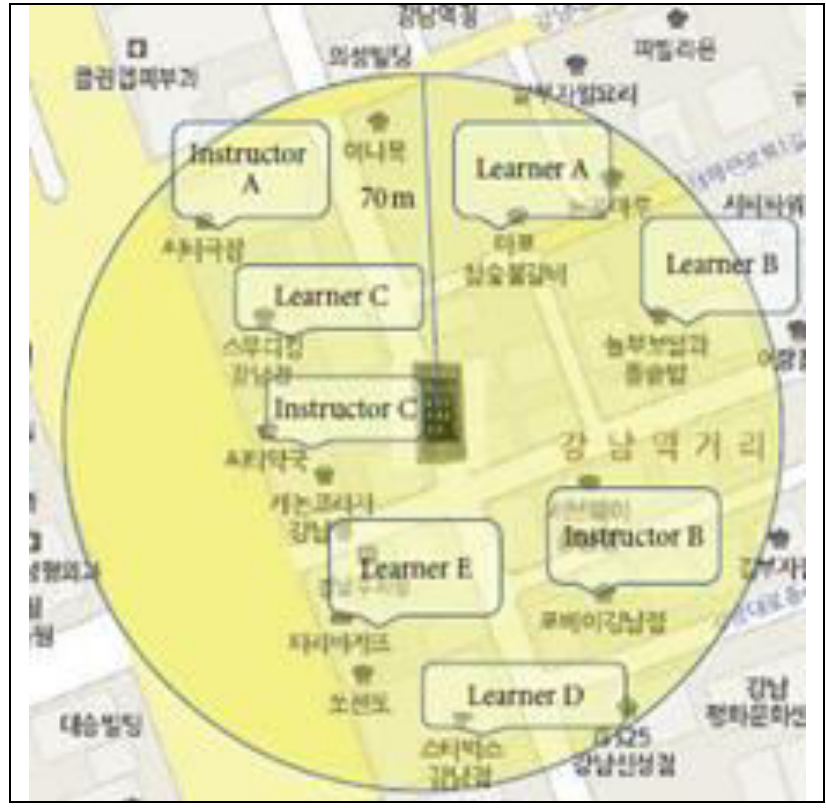

Figure 5: Map Nodes

The second module is getting some location information using the GPS of the mobile device, this information as latitude and longitude of specific point and this can be considered as data entry field also, but it will be dynamic based on the location of the user. The third module here is matching algorithm, which will do two main functions. The first one is matching the interests of the users and displaying the results based on these interests. The second one is displaying the results and sorting it based on the nearest user.in addition to routing information. The application of this research will be simple but helpful and reliable for e-learners, and the next flow chart shown in figure 6 illustrates the main flow of the application and how it will operate simply. Also it is needed to say that elearning based on a distributed learning environment, a social network plays a more important role in support of the learners' learning. Through strengthening connections and inspiring communications among the learners, the learning of the whole community is promoted.

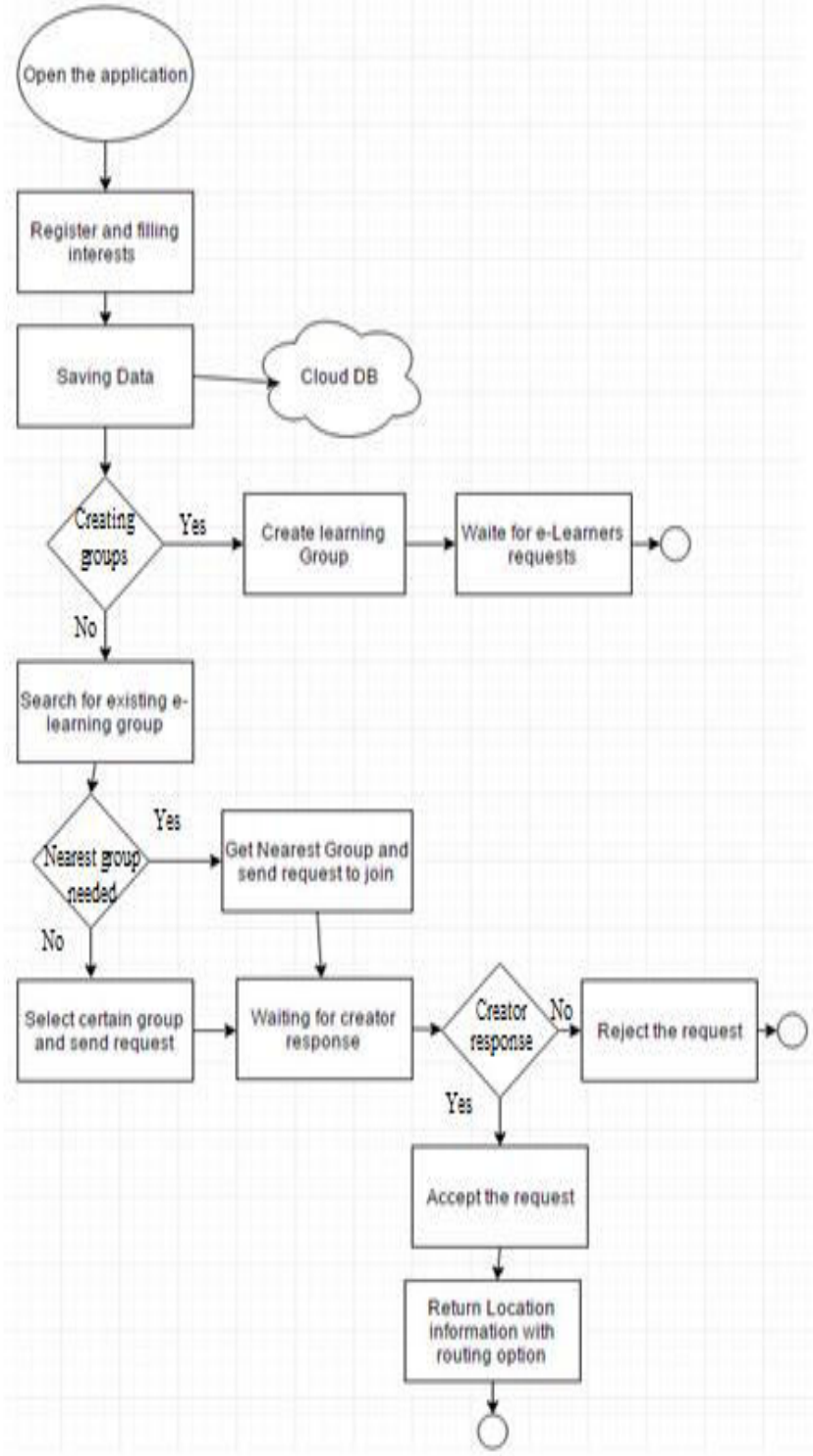

Figure 6: Application workflow

Wegerif [14] highlights the importance of the social side of learning when designing a course, more specifically in an asynchronous learning network. Studies of social networks show that a social network exerts its effect on learning processes and effectiveness [14] and [15]. Figure 6 presents the workflow of the application that is implemented in order to achieve the proposed approach for collaborative e-learning. As stated before, there will be a part of the application and research that will take care of data entry and data collection, and this will happen during the registration of e-learners and creating learning groups. The data will be divided into two parts: 1) data about the user and the fields that the e-learners interested in. 2) the GPS and location data which will be provided by the mobile device and its sensors. 


\section{CONCLUSION}

This paper presents an approach for the collaborative elearning throughout social networks. The proposed approach uses mobile applications, GPS, and matching algorithms to identify the learning interests of the elearners to let them share the same type of information regarding an educational context. The proposed approach uses the three modules to with an applied mobile application workflow for collecting and sharing data from different data sources.

\section{REFERENCES}

[1] C. Gütl, \& V. Chang. (2008). The use of Web 2.0 Technologies and Services to support E-Learning Ecosystem to develop more effective Learning Environments. In Proceedings

[2] Q. Tan, Y. L. Jeng, \& Y. M. Huang. (2010, July). A collaborative mobile virtual campus system based on location-based dynamic grouping. In Advanced Learning Technologies

[3] P. Pocatilu, F. Alecu, \& M. Vetrici. (2010). Measuring the efficiency of cloud computing for elearning systems. WSEAS Transactions on Computers, 9(1), 42-51

[4] N. A. Christakis, \& J. H. Fowler. (2009). Connected: The surprising power of our social networks and how they shape our lives. Little, Brown.

[5] D. Boyd. 2004. "The characteristics of successful online students", New Horizons in Adult Education, vol.18, no. 2 , pp.31-3

[6] E. Fredericksen, A. Pickett, P. Shea, W. Pelz, and K. Swan. (2000) "Learner satisfaction and perceived learning with on-line courses: principles and examples from the SUNY

[7] L. Y. Muilenburg and Z. L. Berge. (2005) "Learner barriers to online learning: a factor analytic study," Distance Education, vol. 26, no. 1, pp. 29-48

[8] G. Zurita, M. Nussbaum, \& R. Salinas (2005). Dynamic Grouping in Collaborative Learning Supported by Wireless Handhelds. Educational Technology \& Society, 8(3), 149-161.

[9] B. Patten, I. A. Sa'nchez, \& B. Tangney (2006). Designing collaborative, constructionist and contextual applications for hand held devices. Computers \& Education, 46, 294-308
[10] M. Michie (1998). Factors influencing secondary science teachers to organize and conduct field trips. Australian Sci. Teacher's J. 44(4)

[11] S. Y. Choi and J. M. Kang. (2012). Adaptive System Supporting Collaborative Learning Based on a Location-Based Social Network and Semantic User Modeling, Volume 2012,

[12] Y. M. Huang, Y. L. Jeng, \& T. C. Huang. (2009). An educational mobile blogging system for supporting collaborative learning. Journal of Educational Technology \& Society, 12(2).

[13] R.M. Felder \& L.K. Silverman (1988). Learning and Teaching Styles in Engineering Education. Engr. Education, 78 (7), 674681

[14] R. Wegerif. (1998) "The social dimension of asynchronous learning Networks," Journal of ALN, vol. 2, no. 1, pp. 34-49

[15] S. R. Hiltz, N. Coppola, N. Rotter, and M. Turoff. (2000) "Measuring the importance of collaborative learning for the effectiveness of ALN: a multimeasure, multi-method 